\title{
Scanning electron microscopic evaluation of dentinal tubule penetration of Epiphany in severely curved root canals
}

\author{
Armita Rouhani ${ }^{1}$, Jamileh Ghoddusi ${ }^{1}$, Neda Naghavi ${ }^{1}$, Ghadir Al-Lawati ${ }^{2}$
}

Correspondence: Dr. Jamileh Ghoddusi

Email: ghoddusij@mums.ac.ir

\begin{abstract}
'Dental Research Center, Department of Endodontics, Faculty of Dentistry, Mashhad University of Medical Sciences, Mashhad, Iran,

${ }^{2}$ General Practitioner, Oman, Oman
\end{abstract}

\section{ABSTRACT}

Objective: The purpose of this study was to compare the depth of dentinal tubule sealer penetration in the apical thirds of severely curved root canals obturated with Resilon/Epiphany self-etch (SE) or gutta-percha/AH Plus using scanning electron microscopy. Materials and Methods: A total of 34 extracted human mandibular molars with $25-40^{\circ}$ curvature of the mesial root canal were selected for this study. After preparation, the mesiobuccal canals were randomly obturated with gutta-percha and AH Plus sealer or Resilon and Epiphany SE sealer. Sealer penetration was evaluated in $2 \mathrm{~mm}$ sections of the apical thirds of roots using scanning electron microscopy. Data were analyzed using the independent $t$-test and Mann-Whitney U-test, with significance set at $P<0.05$. Results: Mean tubular penetration depth did not differ significantly between Resilon SE $(172.22 \mu \mathrm{m})$ and AH Plus $(122.18 \mu \mathrm{m}$; $P>0.05)$. The density of sealer tags in the apical thirds of root canals was also equivalent $(P>0.05)$. Conclusion: Average penetration into dentinal tubules in the apical thirds of severely curved roots did not differ significantly between Epiphany SE and AH Plus.

Key words: Curved canal, Epiphany, Resilon, scanning electron microscopy, sealer penetration

\section{INTRODUCTION}

Successful endodontic treatment depends on the elimination of pulp tissue, bacteria and their byproducts and necrotic debris from the root canal system, in addition to the entombment of any residual bacteria and the creation of an adequate seal to prevent reinfection of the root canal space. ${ }^{[1,2]}$ These goals can be predictably achieved in straight canals, but they can be very difficult to achieve in severely curved canals. ${ }^{[3,4]}$ Errors such as ledge formation, blockage, perforation and apical transportation have been observed during the preparation of curved root canals and the disinfection and removal of infected pulp tissue and bacteria can be more difficult in such canals. ${ }^{[5]}$ Thus, complete coronal and apical sealing of the root canal system is a critical factor when treating severely curved root canals.
Gutta-percha has been used traditionally for root canal obturation. However, it does not bond to root dentin and does not completely seal the root canal system. ${ }^{[6]}$ Resilon (Pentron Clinical Technologies, LLC, Wallingford, CT, USA) is a synthetic, thermoplastic, polymer-based material that was introduced to the market for the obturation of root canal spaces in endodontically treated teeth. Resilon was developed to enable the creation of an adhesive bond between the solid core material and the sealer. It is designed to be used with Epiphany (Pentron Clinical Technologies, LLC), a resin sealer with dentin-bonding capacity. ${ }^{[7,8]}$ Recently, a self-etch (SE) version of this sealer (Epiphany SE) was developed for use with the Resilon core material.

Sealer adhesion to the core material and root surface may reduce microleakage and penetration into

\footnotetext{
How to cite this article: Rouhani A, Ghoddusi J, Naghavi N, Al-Lawati G. Scanning electron microscopic evaluation of dentinal tubule penetration of Epiphany in severely curved root canals. Eur J Dent 2013;7:423-8.

Copyright $\odot 2013$ Dental Investigations Society. DOI: $10.4103 / 1305-7456.120673$
} 
dentinal walls. ${ }^{[7,9]}$ Resilon has also been shown to increase the depth of sealer penetration during lateral compaction in comparison with gutta-percha. ${ }^{[10]}$ Sealer penetration into dentinal tubules is considered to be potentially beneficial because it increases the interface between the core material and dentinal walls, which may improve the mechanical retention of the material via sealer plug interlocking inside the tubules. ${ }^{[11]}$ Furthermore, the sealer's antibacterial activity effectively eliminates bacteria and those remaining inside dentinal tubules are entombed. ${ }^{[12]}$ The ability of a sealer to penetrate dentinal tubules consistently and effectively is one of many factors influencing the choice of material for root canal filling. ${ }^{[13]}$ However, most studies ${ }^{[14-17]}$ have assessed dentinal tubule penetration of root canal sealers in single-rooted teeth, which does not simulate clinical situations such as the treatment of curved root canals in maxillary or mandibular molars. Thus, this study was designed to compare the tubular penetration depths of AH Plus (Dentsply Maillefer, Ballaigues, Switzerland) and Epiphany SE root canal sealers in the apical portions of severely curved canals. The null hypothesis was there is no significant difference in the penetration depths of Epiphany SE and $\mathrm{AH}$ Plus into the dentinal tubules in severely curved canals.

\section{MATERIALS AND METHODS}

A total of 32 extracted human mandibular first and second molars with $25-40^{\circ}$ mesial canal curvature (determined using the Schneider technique ${ }^{[18]}$ ) and type IV anatomic configuration (two separate root canals from orifice to apical foramen, according to Vertucci's classification ${ }^{[19]}$ ) were selected for this study. All teeth were carefully examined to confirm the absence of cracks, resorption, root caries and immature apices. The specimens disinfected using $10 \%$ formalin solution for $1 \mathrm{~h}$ and then kept in distilled water until required.

\section{Specimen preparation}

The crowns of all teeth were removed to a standardized root length of $14 \mathrm{~mm}$ and the distal roots were removed completely. A \#10 K-file was inserted into the mesiobuccal canal until its tip was just visible at the apical foramen and the working length was established $1 \mathrm{~mm}$ short of the measured length. The mesiobuccal canals were prepared using the hybrid technique with hand files and ProTaper Ni-Ti rotary instruments (Dentsply, Tulsa Dental, Tulsa, OK, USA) by $S x, F 1, F 2$ and 25/0.02 hand file at the working length. $\mathrm{NaOCl}$ (5.25\%) (Barfetan, Mashhad, Iran) was applied as an irrigant between the uses of each instrument. RC-Prep (MD-ChelCream; Meta Biomed Co. Ltd., Chunglouk, Korea) was used as a lubricant with each successive file. For smear layer removal, $5 \mathrm{ml} \mathrm{17 \%}$ ethylenediaminetetraacetic acid (EDTA) (Merck, Frankfurt, Germany) was placed in canals for $1 \mathrm{~min}$ and the canals were then irrigated with $5 \mathrm{ml} \mathrm{5.25 \%} \mathrm{NaOCl}$. Final irrigation was performed with sterile water. All canals were dried with paper points (ARIADENT, Asia Chemi Teb, Tehran, Iran) and randomly divided into two experimental groups ( $\mathrm{G}$ and $\mathrm{R} ; n=15$ each); two additional teeth served as control specimens.

In Group G, 25/0.02 Gutta-percha master cone (Gapadent Co., Ltd., South Korea) coated with AH Plus sealer was inserted to the working length. Lateral compaction using accessory cones (size 20/0.02) coated with sealer was performed until the entire root canal was filled. In Group R, 25/0.02 Resilon master cone coated with Epiphany SE sealer (Pentron Clinical Technologies, LLC), was inserted to the working length. Obturation of the root canal system was performed in the same manner as in Group G. After cutting excess material from the Resilon cone, the obturated coronal surface was light cured for $40 \mathrm{~s}$. To allow the material to set, all specimens were kept in an incubator for 3 days at $37^{\circ} \mathrm{C}$ and $100 \%$ humidity.

Each tooth was then sectioned perpendicular to its long axis at 4 and $6 \mathrm{~mm}$ from the anatomic apex to obtain one apical specimen from each root. Sectioning was performed at slow speed under water-cooling with a $0.3 \mathrm{~mm}$ thick diamond disc (Struers; Rodovre, Copenhagen, Denmark). After soaking in an ultrasonic cleaner to remove any debris, the sections were immersed in a solution of $2 \%$ paraformaldehyde and $2.5 \%$ glutaraldehyde in phosphate buffer at $\mathrm{pH} 7.4$ and stored at $40^{\circ} \mathrm{C}$ for $12 \mathrm{~h}$. Then, the specimens were dried with hexamethyldisilazane for $30 \mathrm{~min}$, embedded in epoxy resin and stored in an oven at $60^{\circ} \mathrm{C}$ for $48 \mathrm{~h}$ until the resin had set. The apical surfaces of the sections were polished with wet $\mathrm{SiC}$ papers of decreasing abrasiveness from 180 to 2500 grit. The discs were immersed in $100 \%$ ethanol for 5 min, demineralized with $6 \mathrm{~N} \mathrm{HCl}$ for $30 \mathrm{~s}$ and deproteinized with $1 \%$ $\mathrm{NaOCl}$ for $10 \mathrm{~min}$. Next, the specimens were sonicated in distilled water for $7 \mathrm{~min}$ and dried for $24 \mathrm{~h}$. The specimens were mounted onto $\mathrm{Al}$ stubs and sputter coated (K550; Emitech, Kent, UK) with a thin gold coating at $20 \mathrm{~mA}$ for $4 \mathrm{~min}$ before observation under 
a scanning electron microscope (scanning electron microscope [SEM]; Vega II XMU; Tescan, Czech Republic).

\section{Microscopic evaluation and analysis}

Each specimen was examined under low magnification to obtain an overall view and an area with a maximum density of sealer penetration was selected. The maximum depth of sealer penetration in this area (in $\mu \mathrm{m}$ ) was measured using the microscope's calibrated measuring tool. Two calibrated and blinded specialists scored the presence and density of sealer tags using the following scale: 0 , absent; 1 , few resin tags in tubules; 2 , resin tags in the majority of tubules [Figure 1].

\section{Statistical analysis}

Data were analyzed using the independent $t$-test and the Mann-Whitney $U$-test, with a significance level of $P<0.05$.

\section{RESULTS}

The negative control specimens showed tubule patency with no material content. In both experimental groups, sealer in the dentinal tubules had a smooth and homogenous appearance. Mean maximum penetration depths of sealers in Groups $G$ and $R$ were $122.18 \pm 89.37 \mu \mathrm{m}$ and $172.22 \pm 235.17 \mu \mathrm{m}$, respectively. No significant difference was observed between groups in the mean penetration depth of sealer in the apical third of the root canal $(P>0.05)$. Sealer tag densities did not differ between groups $(P>0.05)$ [Table 1$]$.

\begin{tabular}{|c|c|c|c|c|}
\hline \multirow[t]{2}{*}{ Sealer } & \multicolumn{3}{|c|}{ Tag score } & \multirow[t]{2}{*}{ Total $(n)$} \\
\hline & 0 (no tag) & 1 (few tags) & 2 (many tags) & \\
\hline AH Plus & 7 & 1 & 6 & 14 \\
\hline Epiphany SE & 3 & 3 & 5 & 11 \\
\hline
\end{tabular}
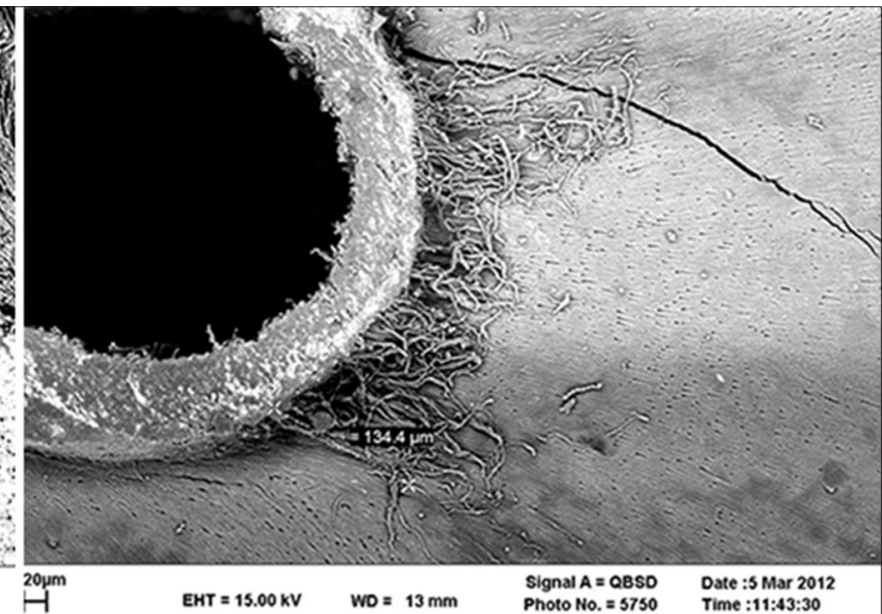

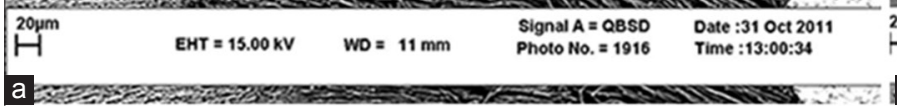

b:

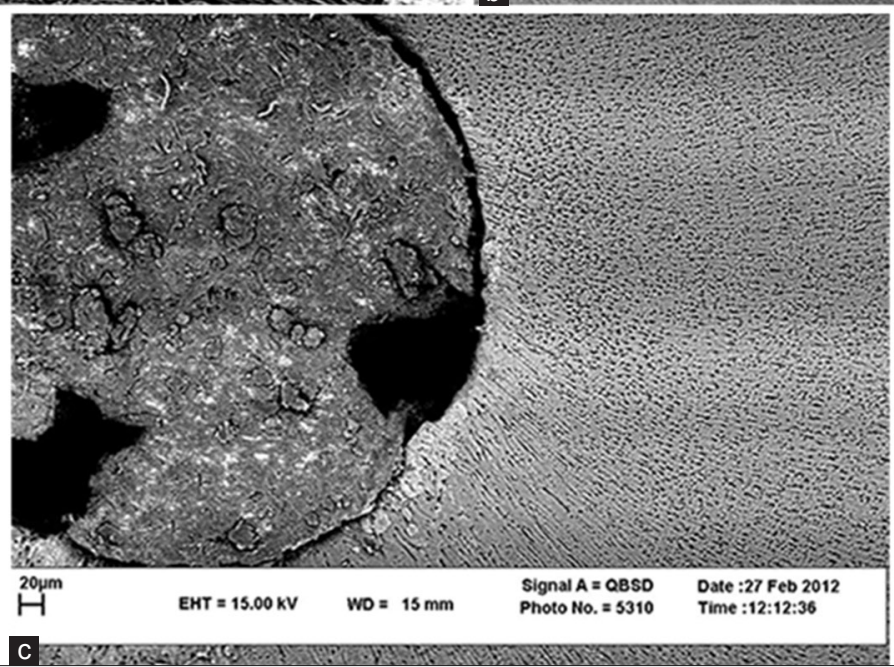

Figure 1: (a) Scanning electron micrograph of a specimen filled with Epiphany self-etch showing numerous resin tags penetrating into dentinal tubules. (b) Specimen filled with AH Plus. Few resin tags are present in the tubules. (c) No penetration of AH Plus into dentinal tubules is visible 


\section{DISCUSSION}

Smear layer removal is considered to be essential for the penetration of any root canal sealer into dentinal tubules. ${ }^{[17]}$ The alternating use of $5 \mathrm{ml} 5.25 \% \mathrm{NaOCl}$ and $17 \%$ EDTA has been recommended for the effective removal of organic and inorganic components of the smear layer ${ }^{[20]}$ and the effectiveness of 1 min irrigation with $3 \mathrm{ml}$ 17\% EDTA for smear layer removal has been demonstrated. ${ }^{[21]}$ Therefore, EDTA was used for a short time $(1 \mathrm{~min})$ in this study to minimize its destructive effects on dentin. ${ }^{[22]}$

Several studies have used SEM to evaluate the dentinal tubule penetration of sealers. ${ }^{[11,23,24]}$ This form of microscopy can be used to measure sealer penetration depth, to observe the surface appearance of sealer in dentinal tubules at high magnification ${ }^{[11]}$ and to determine the density of sealer tags. However, the inability to obtain a detailed overall view at low magnification is the main disadvantage of this technique. The potential for artifact production during the preparation of specimens for SEM must also be considered. ${ }^{[13]}$ Different methods have been used to remove debris and organic matrix around sealer tags and to demineralize horizontal sections for SEM analysis. ${ }^{[25,26]}$ In the current study, to avoid some of these potential artifacts, the samples were embedded in epoxy resin and surface impurities were removed by sonication.

Several studies have documented regional variation in the depth of sealer penetration, ${ }^{[27,28]}$ with the greatest depths measured in the middle thirds of root canals. However, previous studies have been performed in straight root canals. ${ }^{[13,27]}$ In the present study, we evaluated apical third sections because of the importance of this area in curved canals. The average penetration depths of Epiphany SE and AH Plus sealers measured in this study $(122.18 \mu \mathrm{m}$ and $172.22 \mu \mathrm{m}$, respectively) were much greater than those reported by Shokouhinejad et al. ${ }^{[29]}$ for the middle thirds of root canals $(21.50 \mu \mathrm{m}$ and $22.07 \mu \mathrm{m}$, respectively). This discrepancy might be attributable to differences in the mode of tooth sectioning (horizontal vs. longitudinal) and the region in which sealer penetration was measured (middle vs. apical third). Shokouhinejad et al. ${ }^{[29]}$ used longitudinal root sections to assess the tubular penetration of sealers, which introduces the possibility of missing areas of deeper penetration because the dentin surrounding the canal cannot be fully observed. ${ }^{[11]}$
Using confocal laser scanning microscopy (CLSM), Gharib et al..$^{[16]}$ measured an average penetration depth of $303.8 \mu \mathrm{m}$ for Epiphany in the apical thirds of horizontal root sections and Patel et al. ${ }^{[15]}$ reported that the mean penetration depth of real seal (Epiphany) was $696.75 \mu \mathrm{m}$ in the apical thirds of roots; these values differ from that obtained for Epiphany in this study $(172.22 \mu \mathrm{m})$. Several factors may explain these conflicting results, including differences in the methodology used to assess sealer penetration depth (SEM vs.CLSM) and the mode of tooth sectioning, which was longitudinal in Patel et al..$^{[15]}$ study and horizontal in Gharib et al. ${ }^{[16]}$ and the present study. As described above, longitudinal sectioning may result in the mismeasurement of sealer penetration depth, depending on the location from which sections are obtained. ${ }^{[13]}$

One disadvantage of horizontal sectioning is that only one or a small number of sections per specimen can be evaluated. This limitation likely underlies disparities in maximum penetration depths and standard deviations of mean values among studies. ${ }^{[11]}$ Another possible reason for the lesser sealer penetration depth measured in this study might be the examination of apical portions of severely curved $\left(25-40^{\circ}\right)$ root canals, in contrast to single-rooted teeth with straight canals.

The average penetration depth of $\mathrm{AH}$ Plus into dentinal tubules measured in this study $(172.22 \mu \mathrm{m})$ was considerably greater than the mean maximum penetration depth of this sealer measured by Kokkas et al. ${ }^{[14]}$ in longitudinal root sections using SEM $(54.6 \mu \mathrm{m})$. Moradi et al. ${ }^{[30]}$ evaluated horizontal root sections using SEM and reported that the mean maximum penetration depth of AH26 sealer in the apical thirds of root canals, achieved within a short period of time, was $520.48 \mu \mathrm{m}$.

The penetration of root canal sealers into dentinal tubules may be influenced by variations in the physical and chemical properties of the sealers. ${ }^{[31]}$ Kokkas et al. ${ }^{[14]}$ found that the maximum penetration depths of AH Plus and Apexit sealers were significantly greater than that of Roth 811. In addition, Mamootil and Messer ${ }^{[13]}$ found significant differences in the penetration depths of three sealer cements: Epoxy resin (AH26), zinc oxide eugenol and methacrylate resin.

Using SEM, Sevimay and Kalayci ${ }^{[32]}$ showed that $\mathrm{AH}$ Plus adapted better to dentin and penetrated more 
deeply into dentinal tubules than did EndoRez root canal sealer from the apical to the coronal thirds of root canals. Both sealers showed poorer adaptation and penetration in the apical thirds than in the coronal and middle thirds of the canals. This difference may be due to the reduced efficiency of smear layer removal in the apical thirds of canals. In addition, the number and size of dentinal tubules and dentinal structure (tubule density) in the apical third as well as the obturation technique employed, may affect sealer adaptation and penetration..$^{[16,30]}$

In the present study, no significant difference in tag density was found between groups. Pawińska et al. ${ }^{[33]}$ reported the presence of single gaps between Resilon and Epiphany as well as between Resilon and dentin. Similar results have been reported by Tay et al. ${ }^{[34]}$ who used SEM to compare the tightness of root canal obturation with the Resilon-Epiphany system and Gutta-percha with AH Plus. In both groups, the authors observed gap-free and gap-containing regions. These gaps are probably created by rapid polymerization contraction, promoted by heat generated during material condensation with a hot plugger. Additional manipulations during insertion of the material into the canal damage the bonds between the filling elements and root dentin. ${ }^{[34,35]}$

In conclusion, Epiphany SE and $\mathrm{AH}$ Plus showed similar tubular penetration and resin tag density in the apical thirds of severely curved root canals. Although, the penetration of root canal sealers into dentinal tubules might be important from a clinical perspective, future studies should evaluate new root canal sealers in clinical situations.

\section{ACKNOWLEDGMENTS}

This article is based on the undergraduate thesis of Dr. Al-lawati (no. 2575). This study was financially supported by the Vice Chancellor for Research of Mashhad University of Medical Sciences.

\section{REFERENCES}

1. Luiten DJ, Morgan LA, Baugartner JC, Marshall JG. A comparison of four instrumentation techniques on apical canal transportation. J Endod 1995;21:26-32.

2. Magura ME, Kafrawy AH, Brown CE Jr, Newton CW. Human saliva coronal microleakage in obturated root canals: An in vitro study. J Endod 1991;17:324-31.

3. Schilder H. Cleaning and shaping the root canal. Dent Clin North Am 1974;18:269-96.

4. Jain N, Tushar S. Curved canals: Ancestral files revisited. Indian J Dent Res 2008;19:267-71.
5. Dewsnup N, Pileggi R, Haddix J, Nair U, Walker C, Varella CH. Comparison of bacterial reduction in straight and curved canals using erbium, chromium: Yttrium-scandium-gallium-garnet laser treatment versus a traditional irrigation technique with sodium hypochlorite. J Endod 2010;36:725-8.

6. Johnson WT, Kulild JC. Obturation of the cleaned and shaped root canal system. In: Cohen S, Hargreaves KM, editors. Pathways of the Pulp. $10^{\text {th }}$ ed. St. Louis, MO: Mosby; 2011. p. 363-83.

7. Shipper G, Ørstavik D, Teixeira FB, Trope M. An evaluation of microbial leakage in roots filled with a thermoplastic synthetic polymer-based root canal filling material (Resilon). J Endod 2004;30:342-7.

8. Tunga U, Bodrumlu E. Assessment of the sealing ability of a new root canal obturation material. J Endod 2006;32:876-8.

9. Shipper G, Trope M. In vitro microbial leakage of endodontically treated teeth using new and standard obturation techniques. J Endod 2004;30:154-8.

10. Nielsen BA, Baumgartner JC. Spreader penetration during lateral compaction of Resilon and gutta-percha. J Endod 2006;32:52-4.

11. White RR, Goldman M, Lin PS. The influence of the smeared layer upon dentinal tubule penetration by plastic filling materials. J Endod 1984;10:558-62.

12. Heling I, Chandler NP. The antimicrobial effect within dentinal tubules of four root canal sealers. J Endod 1996;22:257-9.

13. Mamootil K, Messer HH. Penetration of dentinal tubules by endodontic sealer cements in extracted teeth and in vivo. Int Endod J 2007; 40:873-81.

14. Kokkas AB, Boutsioukis ACh, Vassiliadis LP, Stavrianos CK. The influence of the smear layer on dentinal tubule penetration depth by three different root canal sealers: An in vitro study. J Endod 2004;30:100-2.

15. Patel DV, Sherriff M, Ford TR, Watson TF, Mannocci F. The penetration of Realseal primer and Tubliseal into root canal dentinal tubules: A confocal microscopic study. Int Endod J 2007;40:67-71.

16. Gharib SR, Tordik PA, Imamura GM, Baginski TA, Goodell GG. A confocal laser scanning microscope investigation of the Epiphany obturation system. J Endod 2007;33:957-61.

17. Ordinola-Zapata R, Bramante CM, Graeff MS, del Carpio Perochena A, Vivan RR, Camargo EJ, et al. Depth and percentage of penetration of endodontic sealers into dentinal tubules after root canal obturation using a lateral compaction technique: A confocal laser scanning microscopy study. Oral Surg Oral Med Oral Pathol Oral Radiol Endod 2009; 108:450-7.

18. Schneider SW. A comparison of canal preparations in straight and curved root canals. Oral Surg Oral Med Oral Pathol 1971;32:271-5.

19. Vertucci FJ. Root canal anatomy of the human permanent teeth. Oral Surg Oral Med Oral Pathol 1984;58:589-99.

20. Baumgartner JC, Mader CL. Ascanning electron microscopic evaluation of four root canal irrigation regimens. J Endod 1987;13:147-57.

21. Moon YM, Shon WJ, Baek SH, Bae KS, Kum KY, Lee W. Effect of final irrigation regimen on sealer penetration in curved root canals. J Endod 2010;36:732-6.

22. Tay FR, Gutmann JL, Pashley DH. Microporous, demineralized collagen matrices in intact radicular dentin created by commonly used calcium-depleting endodontic irrigants. J Endod 2007;33:1086-90.

23. Vassiliadis LP, Sklavounos SA, Stavrianos CK. Depth of penetration and appearance of Grossman sealer in the dentinal tubules: An in vivo study. J Endod 1994;20:373-6.

24. Calt S, Serper A. Dentinal tubule penetration of root canal sealers after root canal dressing with calcium hydroxide. J Endod 1999;25:431-3.

25. Perdigão J, Lopes MM, Gomes G. Interfacial adaptation of adhesive materials to root canal dentin. J Endod 2007;33:259-63.

26. Mannocci F, Innocenti M, Ferrari M. Stereomicroscopic and scanning electron microscopic study of roots obturated with vertically condensed gutta-percha, epoxy resin cement, and dentin bonding agent. J Endod 1998;24:397-400.

27. Weis MV, Parashos P, Messer HH. Effect of obturation technique on sealer cement thickness and dentinal tubule penetration. Int Endod J 2004;37:653-63.

28. Sen BH, Pişkin B, Baran N. The effect of tubular penetration of root canal sealers on dye microleakage. Int Endod J 1996;29:23-8.

29. Shokouhinejad N, Sabeti M, Gorjestani H, Saghiri MA, Lotfi M, Hoseini A. Penetration of Epiphany, Epiphany self-etch, and AH plus into dentinal tubules: A scanning electron microscopy study. J Endod 2011;37:1316-9. 
Rouhani, et al.: Dentinal tubule penetration of Epiphany in curved canals

30. Moradi S, Ghoddusi J, Forghani M. Evaluation of dentinal tubule penetration after the use of dentin bonding agent as a root canal sealer. J Endod 2009;35:1563-6.

31. Okşan T, Aktener BO, Sen BH, Tezel H. The penetration of root canal sealers into dentinal tubules. A scanning electron microscopic study. Int Endod J 1993;26:301-5.

32. Sevimay S, Kalayci A. Evaluation of apical sealing ability and adaptation to dentine of two resin-based sealers. J Oral Rehabil 2005;32:105-10.

33. Pawińska M, Kierklo A, Marczuk-Kolada G. New technology in endodontics: The Resilon-Epiphany system for obturation of root canals. Adv Med Sci 2006;51 Suppl 1:154-7.

34. Tay FR, Loushine RJ, Weller RN, Kimbrough WF, Pashley DH, Mak YF, et al. Ultrastructural evaluation of the apical seal in roots filled with a polycaprolactone-based root canal filling material. J Endod 2005;31:514-9.
35. Gesi A, Raffaelli O, Goracci C, Pashley DH, Tay FR, Ferrari M. Interfacial strength of Resilon and gutta-percha to intraradicular dentin. J Endod 2005;31:809-13.

\begin{tabular}{|l|l|}
\hline \multicolumn{2}{|c|}{ Access this article online } \\
\hline Quick Response Code: & $\begin{array}{l}\text { Website: } \\
\text { www.eurjent.com }\end{array}$ \\
\cline { 2 - 2 } & $\begin{array}{l}\text { Source of Support: Vice Chancellor of } \\
\text { Mashhad University of Medical Sciences. } \\
\text { Conflict of Interest: The authors deny any } \\
\text { conflict of interest related to this study }\end{array}$ \\
\hline
\end{tabular}

\section{New features on the journal's website}

\section{Optimized content for mobile and hand-held devices}

HTML pages have been optimized of mobile and other hand-held devices (such as iPad, Kindle, iPod) for faster browsing speed.

Click on [Mobile Full text] from Table of Contents page.

This is simple HTML version for faster download on mobiles (if viewed on desktop, it will be automatically redirected to full HTML version)

\section{E-Pub for hand-held devices}

EPUB is an open e-book standard recommended by The International Digital Publishing Forum which is designed for reflowable content i.e. the text display can be optimized for a particular display device.

Click on [EPub] from Table of Contents page.

There are various e-Pub readers such as for Windows: Digital Editions, OS X: Calibre/Bookworm, iPhone/iPod Touch/iPad: Stanza, and Linux: Calibre/Bookworm.

\section{E-Book for desktop}

One can also see the entire issue as printed here in a 'flip book' version on desktops.

Links are available from Current Issue as well as Archives pages.

Click on View as eBook 